\title{
Neomycin Sulfate/Polymyxin B Sulfate/Dexamethasone
}

National Cancer Institute

\section{Source}

National Cancer Institute. Neomycin Sulfate/Polymyxin B Sulfate/Dexamethasone. NCI

Thesaurus. Code C121617.

A topical combination preparation containing the sulfate salt form of the aminoglycoside antibiotic neomycin, the sulfate salt form of the polypeptide antibiotic polymyxin $B$, and the glucocorticoid dexamethasone, with antimicrobial, anti-infective and antiinflammatory activities. Upon topical application, neomycin irreversibly binds to the bacterial 30S ribosomal subunit, thereby preventing mRNA from binding, causing both misreading and the inhibition of protein synthesis. Polymyxin B binds, with its positively charged amino groups, to negatively charged phospholipids in the outer cell membrane of Gram-negative bacteria, thereby disrupting cell wall integ rity and altering the permeability of the bacterial cytoplasmic membrane. Dexamethasone binds to the cytoplasmic glucocorticoid receptor, and this receptor-ligand complex is translocated to the nucleus where it initiates the transcription of genes encoding for anti-inflammatory mediators, such as cytokines and lipocortins. 